\title{
Experimental Evidence for the Existence of an External World
}

\author{
Eric Schwitzgebel \\ Department of Philosophy \\ University of California at Riverside \\ Riverside, CA 92521-0201 \\ eschwitz at domain: ucr.edu \\ Alan T. Moore \\ Department of Philosophy \\ University of California at Riverside \\ Riverside, CA 92521-0201
}

March 19, 2013 


\title{
Experimental Evidence for the Existence of an External World
}

\begin{abstract}
$\underline{\text { Abstract: }}$
In this essay I attempt to refute radical solipsism by means of a series of empirical experiments. In the first experiment, I prove to be a poor judge of four-digit prime numbers, in contrast to a seeming Excel program. In the second experiment, I prove to have an imperfect memory for arbitrary-seeming three-digit number and letter combinations, in contrast to my seeming collaborator with seemingly hidden notes. In the third experiment, I seem to suffer repeated defeats at chess. In all three experiments, the most straightforward interpretation of the experiential evidence is that something exists in the universe that is superior in the relevant respects - theoretical reasoning (about primes), memorial retention (for digits and letters), or practical reasoning (at chess) - to my own solipsistically-conceived self.
\end{abstract}




\section{Experimental Evidence for the Existence of an External World}

It occurs to me to wonder whether the external world exists - that is, whether anything exists other than my own stream of conscious experience. Radical solipsism, I'll say, is the view that my conscious mind is the only thing in the universe; there are no material objects, no other minds, not even a hidden unconscious side of myself. On radical solipsism, this [here I gesture inwardly at my sensory, emotional, and cognitive experiences] is all there is, nothing more. I find myself, now, contemplating radical solipsism. I want some sort of evidence or proof of its falsity.

You might think - if you exist - that my desire for proof is foolish. You might think it plain that I could never show radical solipsism to be false, that I (and you and we) can only assume that it's false, that any attempt to prove solipsism wrong would inevitably turn in a circle. You might think, with (my seeming memory of) Wittgenstein (1950-1951/1974), that the existence of an external world is an unchallengeable framework assumption necessary for any inquiry to make sense, that it's a kind of philosophical disease to want to rationally refute solipsism, that I might as well hope to establish the validity of logic using no logical assumptions

or to prevent my falling through the ice by tugging up on my belt. Now I'll grant that I might be philosophically sick. There's something admittedly crazy about solipsistic doubt. But it's not entirely clear to me, at least not yet, that I can't find my cure from within the disease, by giving my sick mind exactly the proof it wants.

At first blush, the historical evidence - or what I think of as the historical evidence looks unpromising. The two most famous attempts to cure solipsism from within come from Descartes, in his Meditations (1641/1984), and Kant, in his "Refutation of Idealism" (from his 
first Critique: 1781/1787/1929). Both appear to be failures. Descartes's proof of the external world requires accepting, as an intermediate step, the very dubious claim that the thought of a perfect God could only arise from a being as perfect as God. ${ }^{1}$ Kant's proof turns on the assertion that I cannot be "conscious of my own existence as determined in time" or conscious of change in my representations unless I perceive some permanent things that actually exist outside of me. This is also a very dubious claim, and one for which he offers no clear argument. Why couldn't a sense of representational change and of my determination in time arise innately or from temporally overlapping experiences or from hallucinatory experiences as of seeing things that exist outside of me $?^{2}$ Most philosophers today, I think, regard as hopeless all such attempts to prove radical solipsism false using as one's starting point only general logic and solipsismcompatible premises about one's own conscious experience.

So we might, with Hume (1740/1978), yield to the skeptic and grant her the argument, then turn our minds aside for a while, play some backgammon, and go on living and philosophizing (on other topics) just as before. Or we might, with Moore (1939), refute the solipsist by proving that the external world exists by means of solipsism-incompatible premises that beg the question. "Here is a hand, here is another, therefore the external world exists; what,

${ }^{1}$ See discussion in Broughton 2002; Nolan and Nelson 2006. Broughton explicitly notes that few readers of the Meditations have found this aspect of Descartes's argument plausible (2002, p. 154).

${ }^{2}$ Kant interpretation is always fraught. However, even sympathetic commentators seem to agree that Kant's argument is problematic, at least if construed as a self-contained argument with the positive conclusion that the external world exists. For charitably amended reconstructions in light of subsequent Kantian texts - excessively charitable, we're inclined to think, and still unsuccessful as proofs - see Guyer 1987 and Dicker 2008. See also Stroud 1984 and 1994 for a more general critique of Kantian "transcendental" refutations of skepticism. I set aside the Transcendental Deduction in part because its conclusion is not as clearly in conflict with the regularity-governed radical solipsism that is our target as are views in which the regularities of the mind are driven by nonconscious brain processing. (Thanks to Pierre Keller and Houston Smit for discussion.) 
you want stronger proof than that?" is really just a refusal to play the intended game. Or we might, with Wittgenstein, try to undercut the very desire for proof. However, none of these responses seems to me to be preferable to actually delivering a non-question-begging proof if one is discoverable. They are all fallback maneuvers. Another type of fallback maneuver, I think, can be found in those recent versions of contextualism and reliabilism that concede to the radical solipsist that we cannot know that the external world exists, once the question of its existence has been raised in a philosophical context, while insisting that we can still nonetheless have ordinary knowledge of the mundane facts of practical life. ${ }^{3}$

The historical landscape has been dominated by these two broad approaches. The first approach aims high, hoping to establish with apodictic or deductive or "transcendental" certainty, in a non-question-begging way, that the external world really does exist. The second approach abandons hope of non-question-begging proofs, seeking in one way or another to make us comfortable with their absence. But there is a third approach, historically less influential, that has not yet, I think, been adequately explored. Its most famous advocate is Bertrand Russell.

Russell writes:

In one sense it must be admitted that we can never prove the existence of things other than ourselves and our experiences.... There is no logical impossibility in the supposition that the whole of life is a dream, in which we ourselves create all the objects that come before us. But although this is not logically impossible, there is no reason whatsoever to suppose that it is true; and it is, in fact, a less simple hypothesis, viewed as a means of accounting for the facts of our own life,

\footnotetext{
${ }^{3}$ See, e.g., Williams 1991; DeRose 1995; Lewis 1996; Dretske 2003.
} 
than the common-sense hypothesis that there really are objects independent of us, whose action on us causes our sensations (1912, p. 22-23, emphasis in original).

Russell also states that certain experiences are "utterly inexplicable" from the solipsistic point of view and that the belief in objects independent of us "tends to simplify and systematize our account of our experiences", and for this reason the evidence of our experience speaks against solipsism, at least as a "working hypothesis" (1912, p. 23-24; 1914, p. 103-104). Russell aims lower than do Descartes and Kant; and partly as a result his goal seems more plausibly attainable. Yet Russell also promises something that the Hume, Wittgenstein, Moore, et al. do not: a non-question-begging positive argument against solipsism. It's a kind of middle path between certainty and surrender or refusal.

Unfortunately, there are two major shortcomings in Russell's argument. One is Russell's emphasis on simplicity. The most natural way to develop the external world hypothesis, it seems, involves committing to the real existence of billions of people, many more billions of artifacts, and naturally-occurring entities vastly more numerous even than that, manifesting in highly complex and unpredictable patterns. On the face of it, it's odd to say that such a picture of the world is simpler than radical solipsism.

The second shortcoming is the uncompelling, gestural nature of Russell's supporting examples. What is it, exactly, that Russell says is "utterly inexplicable" for the solipsist? It is a cat's seeming hunger, after an interval during which the cat was not experienced:

if [the cat] does not exist when I am not seeing it, it seems odd that appetite should grow during non-existence as fast as during existence. And if the cat consists only of sense-data, it cannot be hungry, since no hunger but my own can be a sense-datum to me. Thus the behaviour of the sense-data which represent the 
cat to me, though it seems quite natural when regarded as an expression of hunger, becomes utterly inexplicable when regarded as mere movements and changes of patches of colour, which are as incapable of hunger as a triangle is of playing football (p. 23, emphasis in original).

To this example, Russell appends a second one: that when people seem to speak "it is very difficult to suppose that what we hear is not the expression of a thought" (p. 24). But are such experiences really so utterly inexplicable for the solipsist? I can begin to frame some possible solipsism-compatible explanations. Maybe I can start by thinking about what seems to happen in dreams. Indeed, Russell's very next sentence expresses the obvious objection from dreams. Dreams arguably can involve apparent hungry cats and apparent human voices. ${ }^{4}$ Appearances of hungry feline behavior, then, if they can happen explicably in dreams, needn't require real feline hunger behind them to be explicable, contra what Russell seems to be assuming in his argument; nor need appearances of human speech require real human minds independent of my own. Although this objection seems to me to be entirely fatal to Russell's argument as stated, Russell appears to be satisfied to give only a cursory, single-sentence response: "But dreams are more or less suggested by what we call waking life and are capable of being more or less accounted for on scientific principles if we assume that there really is a physical world" (p. 24). The inadequacy of this response is revealed by the fact that the solipsist can say something quite similar: If I assume solipsism then I can account for the appearances of the cat and the interlocutor as imperfect projections of myself upon my imagined world, grounded in what I

\footnotetext{
${ }^{4}$ I have to admit, however, some attraction to the view that dreams typically involve not perceptual experiences but rather imagery experiences (Ichikawa 2009). I don't think that affects my general complaint against Russell's argument, however. If necessary, the arguments of this paragraph could be reframed using hallucination, or the solipsist explanation could even be sui generis without an obvious parallel in commonsense views about the ordinary causes of nonveridical experience.
} 
know about myself though introspection. Such an explanation is sketchy, to be sure, but so also - notoriously - is the current scientific explanation of dreams. At best, Russell's argument is problematically underdeveloped.

Although I am dissatisfied with (what I think of as) Russell's particular argument, as I sit here (or seem to) with my solipsistic doubts, I still feel the attraction of that general approach. The core idea I want to preserve is this: Although in principle (contra Descartes and Kant) all the patterns in my experience are compatible with the non-existence of anything behind that experience, I still can entertain two competing hypotheses about the origins of those experiences: the solipsistic hypothesis according to which all there is in the universe are those experiences themselves, and the external world hypothesis which holds that there is something more. I can then consider these hypotheses not by the standards of apodictic or transcendental proof, but rather as something like scientific hypotheses, with epistemic favor accruing to the one that appears to do the better job accounting for the experiential evidence at hand. Although Russell's own remarks are too cursory, that doesn't speak against the general project. Indeed, it invites the hope that a more patient effort might still bear fruit. ${ }^{5}$

I hope to take Russell's approach one step farther. Russell treats the solipsistic hypothesis and the external world hypothesis as scientific or quasi-scientific hypotheses that have different theoretical virtues and vices when confronted with the task of explaining his apparent sensory experiences. But neither he nor later philosophers sympathetic with this

${ }^{5}$ Some other recent epistemologists have also endorsed such a project, including Laurence BonJour (1985, 2002), Jonathan Vogel (1990, 2005, 2008), Christopher Peacocke (2004), and James Beebe (2009). However, their efforts tend to focus on powerful-deceiver skepticism rather than radical solipsism (even a deceiver is disallowed by radical solipsism). Also, like Russell, they do not consider specific pieces of solipsistically-available data evaluated scientifically via forward-looking predictive test. See also my discussion of Reichenbach 1938/2006 and Sober 2011 in Schwitzgebel 2013. 
general approach actually empirically test the two competing hypotheses, to see which hypothesis makes more accurate predictions given plausible solipsism-compatible auxiliary assumptions. No one in the tradition - or rather, I should say, no apparent person in what I think of as the tradition - sets up an actual series of experiments, in formal scientific style, pitting the two hypotheses against each other in a non-question-begging way and then quantitatively analyzing the results. No one transforms Russell's vaguely scientific appeal into actual experimental philosophy. That is what I aim to do in this essay.

In other words, I aim to do some solipsistic science. There is no contradiction in this, I think. Skepticism about the external world is one thing, skepticism about induction and scientific reasoning quite another. I aim to see whether, from assumptions and procedures that even a radical solipsist can admit, I can generate experimental evidence for the existence of an external world.

Let me emphasize: I don't hope to prove something from nothing. The skeptic's position is unassailable if his opponent must prove all the premises of any potential argument. All scientific procedures must rest on some background assumptions that are taken for granted. I aim to refute not all of skepticism, but rather only radical solipsism. I aim only to move from solipsism-compatible premises to an anti-solipsistic conclusion. That, I think, would be interesting enough and victory enough. Consequently, for purposes of this project, I don't plan to entertain any more than the usual doubt about (solipsism-compatible versions of) induction or deduction or memory or introspective self-knowledge.

More specifically, I will allow myself to assume the following:

- introspective knowledge of sensory experience and of other happenings in the stream of experience; 
- memories of past experience from the time of the beginning of the series of experiments (but not before);

- concepts and categories arrived at I-know-not-how and shorn of any presupposition of grounding in a really-existing external world;

- the general tools of reason and scientific evaluation to the extent those rules don't build in any assumptions about affairs beyond my stream of experience.

Leaning only on these resources, I will try to establish, to a reasonable standard of scientific confidence, the existence of an external world.

If solipsism implies that I have complete control over my stream of experience, it would be easy to refute experimentally. I might, for example, take in my hands a deck of cards (or at least seem to myself to do so) and resolutely will that I draw a queen of clubs. Then I might note the failure of the world to comply with my will. In fact, I have now attempted exactly this, with an apparent ten of diamonds as my result. But unfortunately for the prospects of such an easy proof, solipsism has no such voluntaristic implications and thus admits of no such antivoluntaristic refutation. ${ }^{6}$

To think through this last issue more clearly, I close my eyes - or rather I do something that seems to me to be a closing of the eyes. What I visually experience is an unpredictable and uncontrollable array of colors against a dark gray background, the Eigenlicht. ${ }^{7}$ This uncompliant Eigenlicht is entirely compatible with radical solipsism as long as I conceptualize the patterns it contains as nothing but patterns in, or randomnesses in, my stream of sensory experience,

\footnotetext{
${ }^{6}$ Certain remarks of Locke (1689/1975, IV.xi) Berkeley (1710/1965, §29 ff.) and Fichte $(1797 / 2000, \S 2)$ suggest a view of solipsism on which the solipsist has full voluntary control of all experience. But such compliant-world solipsism is a flimsy cousin of the more robust version of solipsism I have in view. See also Descartes 1641/1984, Meditations 3 and 6.

${ }^{7}$ For more on visual experience with one's eyes closed, including the question of controllability, see Schwitzgebel 2011, ch. 8.
} 
patterns governed by their own internal coherences rather than by anything further that stands behind them. The unpredictability and uncontrollability of these visual patterns no more compels me to accept the existence of non-experiential objects than irresolvable randomness and unexplained laws in the material world, as I conceptualize it, would compel me to accept the existence of immaterial objects behind the material ones.

What sorts of tests, then, might put radical solipsism at risk? Interpreting this question as straightforwardly as possible, I see three types of potential evidence that would be difficult to accommodate on a solipsistic view: evidence of the existence of something with theoretical reasoning powers that exceed my own, evidence of the existence of something that can retain its properties over a period during which those properties are lost to my sensory experience and memory, and evidence of something with practical reasoning powers that exceed my own.

I will now describe three experiments, all conducted in one uninterrupted episode on a single day. To the extent possible, the remaining text, apart from the final concluding section, reflects real thoughts on the day of experimentation, with a few subsequent modifications for clarity. To fit all of these thoughts into the time-span of a single day, I drafted a version of the material below in the present tense using dummy results based on pilot experiments. I entered into the experiment with the intention of genuinely thinking the thoughts below with real data as the final results came in. Where the results surprised me, I of course had to modify my thinking.

\section{Experiment 1: The Prime Number Experiment.}

Method. I have prepared for this experiment by doing something that seems to me to be an instance of programming Microsoft Excel to calculate whether a four-digit number is prime, displaying "prime" next to the number if it is prime and "nonprime" if it is not. Then I did 
something that seemed to me to be programming Microsoft Excel to generate arbitrary numbers between 1000 and 4000, excluding numbers divisible by 2, 3, and 5. Version A of this experiment will proceed in four stages, if all goes according to plan. First, I will generate a fresh set of 20 new qualifying four-digit numbers. Second, I will take my best guess at which of those 20 numbers are prime, allotting myself approximately two seconds for each guess. Third, I will paste this set of numbers into my seeming prime number calculator function, noting which ones are marked as prime by the seeming machine. Finally, by laborious hand calculation, I will determine which among those twenty numbers actually are prime. Version B will proceed the same way, except using Roman numerals as the initial basis for my guesses.

My hypothesis is this: If nothing exists in the world apart from my stream of conscious experience, then the swift, seemingly Excel-generated answers should not be statistically more accurate than my own best guesses. For if they were more accurate, that would suggest that something exists in the world that has calculation powers that exceed my own.

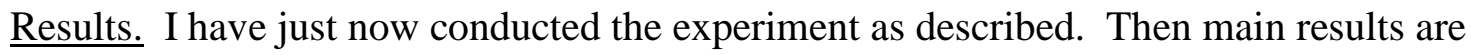
displayed in Figure 1. For Version A, my best guesses yielded an estimate of 11 primes. In most cases, this felt like simple hunchy guessing, though 3913 did pop out as nonprime. The apparent Excel calculation also yielded an output of 11 seemingly machine-calculated primes.

Subsequent hand calculation confirmed the seeming machine results in 19 out of the 20 cases. (I leave it open for purposes of the experiment whether the failure of match in one case reflects computational error on my part. $^{8}$ ) In contrast, hand calculation confirmed my best-guess judgments in only 11 out of the 20 cases. The difference in accuracy between 19/20 and 11/20 is statistically significant by Fisher's exact test (hand calculated), with a two-tailed p value of $<.02$.

${ }^{8}$ Subsequent examination of my notes suggests a long-division error on my part and thus that the apparent Excel output was correct after all. 
For Version B, again both my best guesses and the apparent Excel outputs yielded 11 estimated primes, and again hand calculation confirmed the apparent Excel outputs in 19 of the 20 cases, ${ }^{9}$ while hand calculation confirmed my best guesses in 13 of the 20 cases. The difference in accuracy between 19/30 and 13/20 is marginally significant by Fisher's exact test (hand calculated), with a two-tailed $\mathrm{p}$ value of approximately $.05 .^{10}$

${ }^{9}$ Subsequent examination of my notes reveals an error in my hand conversion from Roman to Arabic numerals.

${ }^{10}$ I did not attempt precise hand calculation of the $\mathrm{p}$ value for this test. Subsequent analysis with a statistical program yields $\mathrm{p}=.044$. For Version $\mathrm{A}$, subsequent analysis yields $\mathrm{p}=$ .008 . 
Figure 1: Accuracy of prime number estimates, as judged by hand calculation, for my best guesses before calculating, compared to what would seem to be the output of an Excel spreadsheet programmed to detect primes. Error bars are hand-calculated $95 \%$ confidence intervals using the normal approximation and a ceiling of $100 \%$.

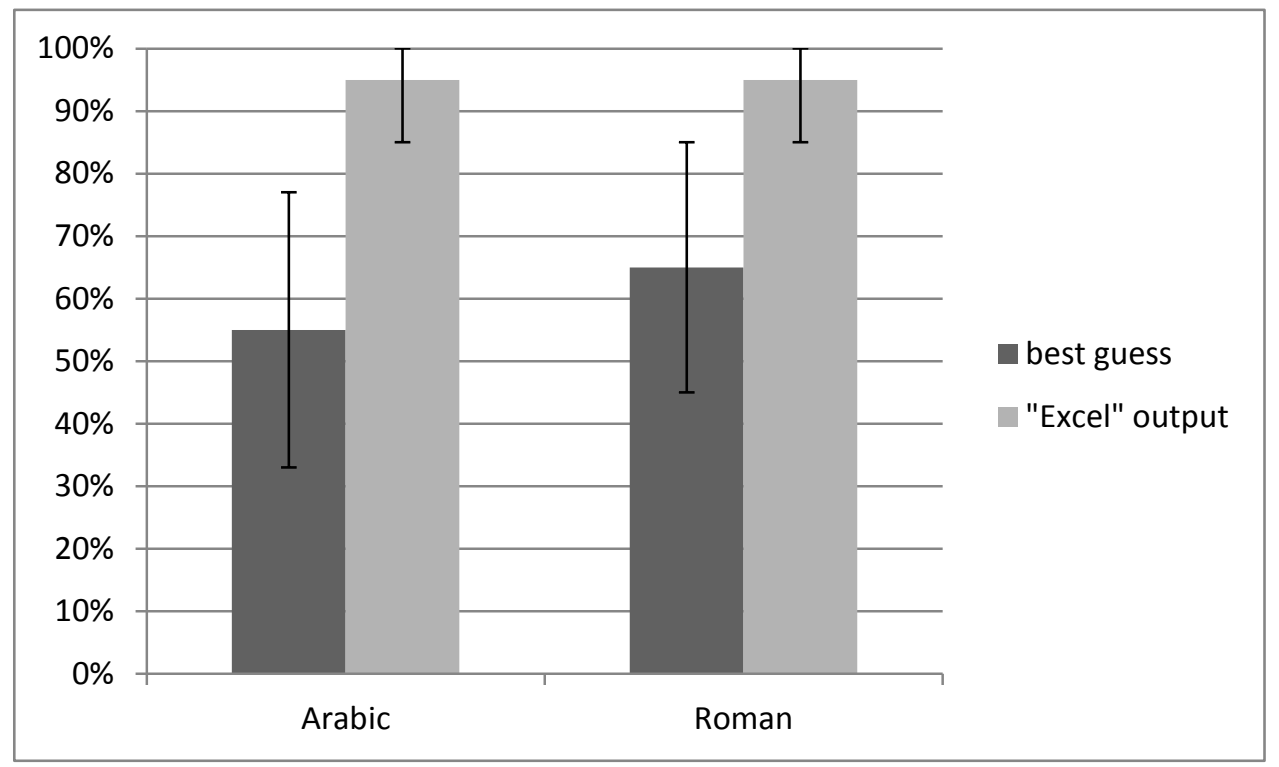


Discussion. I believe the most natural interpretation of these results is that something exists in the external world that has calculation capacities exceeding my own.

I set aside radically skeptical concerns about memory (what if the world was created two seconds ago?) and introspection ${ }^{11}$ (what if I delusionally misjudged all my intentions and/or sensory experiences?). My aim, as I have emphasized, is not to employ radically skeptical standards generally, but rather to employ (what I think of as) the normal standards of science insofar as they can be employed by someone open-minded about radical solipsism. I also set aside concerns about whether this seeming computer really calculates rather than only being designed to give outputs interpretable by users as the results of calculation. ${ }^{12}$ Either way, the results suggest the existence of someone or something with prime-number-detection capacities that exceed those present in my solipsistically-conceived stream of experience. That thing might even be my own unconscious mind, bent on tricking my conscious mind into misinterpreting my experimental results. No problem! Radical solipsism as I've defined it would still be false, since radical solipsism denies the existence of anything outside of my stream of experience, even if only my own unconscious mind.

As I reflected earlier, I believe that solipsism can readily allow that the stream of experience contains patterns within it, as long as those patterns are not caused by anything behind that experience. The anti-solipsistic interpretation of these results thus turns crucially on

${ }^{11}$ If you exist you might think that much of what I am doing in this experiment is perception, not introspection; and if we reject introspective foundationalism, then ordinary perceptual judgments in no way depend, either causally or epistemically, on introspective judgments. But from within the perspective of this project I intend that my judgments be not perceptual judgments about the outside world but rather introspective judgments about my experiences of that seeming outside world - however easy it might be to slide between the two types of judgment when I'm not keeping the distinction firmly in mind. See Schwitzgebel 2012 for more discussion of the relationship between perception and introspection.

${ }^{12}$ See Searle 1980, 1984. 
the question of whether the outcome of this experiment might plausibly be only a manifestation of such solipsistic patterns of experience. So: How plausible would such a pattern be, really, given solipsistic assumptions? What should I expect patterns of experience to look like if solipsism is true?

These are hard questions to answer. And yet I don't want to be too hard on myself. I'm looking only for scientific plausibility, not absolute certainty.

One typical kind of pattern in experience, it seems to me, is this: When I do something that feels like shifting my eyes to the left, my experienced visual field seems to shift to the right - a fairly simple law of experience, a simple way in which two experiences might be directly related with no compelling explanatory need of a non-experiential intermediary. Likewise, when I seem to see a spherical thing and then seem to reach out to touch it, I seem also to have tactile experience of something spherical. This pattern is somewhat more complex, and not fully expressible by me, but still it seems a fairly straightforward set of relationships among experiences. It's tempting to think that there must be a genuine mind-independent physical sphere that unifies and structures those cross-modal experiences. But if I am to be genuinely open-minded about solipsism, I think I must admit that the existence of a radically new ontological type is a heavy cost to pay to explain this set of experiences. They might be related to each other directly by an admittedly somewhat complex set of intrinsically experiential laws (as in Mill 1867). Similarly when I close my eyes. There are regularities - the visual field changes radically in roughly the way I expect, though it also gains some highly unpredictable elements. Solipsism can also allow, I think, the existence of unrecognized patterns of relationship among my experiences. For example, afterimages of bright seeming-objects might be in perfect complementary colors even if I don't realize that fact. There might be discernible 
but as-yet-undiscerned regularities governing temporal evolutions in the flight of colors I experience when my eyes are closed. All of this seems plausibly explicable by solipsistic laws that relate experiences directly, one to another. And all of this I was ready to admit before I began my experiment. I am simply reminding myself. I intended that my experiment tap into something different.

To explain the results of Experiment 1 solipsistically via such unmediated laws of experience, something like the following would have to be true. There would have to be an unmediated relationship between, on the one hand, (a.) the visual experience, for example, of the numeral "2837" in apparent black Calibri 11 font in an apparent Excel spreadsheet, accompanied by the inner speech experience of saying to myself, with understanding, "twenty-eight thirtyseven" in English, and, on the other hand (b.) the visual experience of suddenly seeing "prime" in the matched column to its right if the number is prime or "nonprime" if the number is nonprime. Such a law would be both semantic and dependent upon facts about primes in a way that I tend to think of as uncharacteristic of scientific laws. In both ways it's quite different from the laws of experience I described in the previous paragraph. Furthermore, such laws would have to work in essentially the same way for Roman numerals too, despite the fact that Roman and Arabic numerals have little in common on the sensory surface. Something in the world seems to be responding, more swiftly than I possibly can, to semantic facts about the primeness of the numbers represented by these different numerals, producing the complex visual shapes "prime" and "nonprime" appropriately in response.

Now maybe this is indeed just a previously unknown type of law of experience. Maybe the primeness of the number represented by the arbitrary visual shape of a numeral can indeed have direct effects on later visual experiences of mine without need of anything beyond my 
stream of experience. But it seems to me rather a strain to think so. It doesn't seem the most natural prediction from a solipsistic point of view. Positing such a law in response to the evidence of Experiment 1 has the scent, I think, of a suspiciously ad hoc maneuver designed to save a theory from what would otherwise be counterevidence - the classic sign of a theory in trouble, per Duhem (1906/1954), Popper (1934/1959), Kuhn (1962/1996), Lakatos (1978) whereas it is just what I would predict if the external world exists and has the sorts of features (like functional spreadsheet programs) that I would like to believe it has.

Given my acknowledged bias against solipsism, though, it would be imprudent to leap too swiftly to the conclusion that solipsism is false from this evidence alone. Maybe this is exactly the sort of law of experience that I should expect on a solipsistic worldview, charitably enough understood. So I have some further experiments in mind.

\section{Experiment 2: Two Memory Tests.}

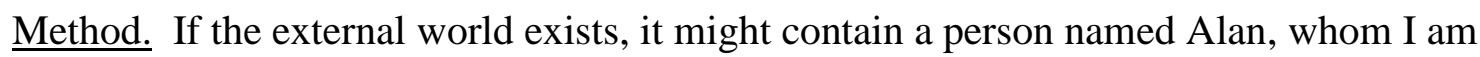
inclined to think of as my graduate student collaborator. I have arranged with this seeming "Alan" that he test my memory. In the first test, he will orally present to me an arbitraryseeming series of 20 three-digit numbers. He will present this list to me twice. I will first attempt to freely recall items from that list, and then I will attempt to recognize those items from among a 40-item list, half of which consists of new three-number combinations. The second test will be the same procedure with 20 sets of three letters each, and with a two-minute enforced delay to further impair my performance. In both cases, I expect that seeming-Alan will tell me that my memory has been less than perfect. He will then, if all goes according to plan, tell me that he is visually re-presenting the original lists. If solipsism is true, nothing should exist to 
anchor the advertised visual "re-presentation" to the earlier orally-presented lists, apart from my own memory. In those cases, then, where my memory has failed, the supposed "re-presentation" should not contain a greater number of the originally presented elements than would be generated by chance. I shouldn't be able to step in the same stream twice except insofar as I can remember that stream (though maybe I could have the illusory feeling of having done so). The contents of experience should not have a fixity that exceeds that of my memory, because there is nothing beyond my own experience that can do the fixing. At least, this seems to me the most straightforward prediction from within the solipsistic worldview.

The final move in the experiment will be to confirm that the re-presented list does indeed match the original list despite the gap in my memory. The method of confirmation will be this: Seeming-Alan will state the procedure by which he generated the seemingly arbitrary lists. By (seeming) prior arrangement, he will have used a simple semantic procedure for the letters and a simple arithmetic procedure for the numbers. (I seem to recall having suggested that he draw his letters from something like the middle three letters of each U.S. state in alphabetical order or that he take a string of text I would recognize and present it backwards, and that he draw his numbers from something like the decimal expansion of $1 / \mathrm{n}$ for some $\mathrm{n}$ that generates a suitably complicated expansion.) I should then be able to confirm that the later-presented full lists of 20 three-element items are indeed consistent with generation by the claimed procedures. This will in turn suggest that the original lists were also generated by those same procedures. It will do so, if all goes well, because (as I will later estimate) there's only a very small chance that two arbitrary lists of 20 three-element items would have several items in common - the several items I hope to remember across the temporal gap - unless they were generated by the same procedure. This would then allow me to infer that the entire "re-presented" list does indeed match the entire 
original list despite my failure to recall some items across the interval - contra the no-samestream prediction of the solipsistic hypothesis.

Results. The main results are displayed in Figure 2. According to seeming-Alan, in the number test, I correctly recalled 7 of the 20 three-digit items (with no false recall) and I accurately recognized 14 of the items. In the letter test, I correctly recalled 8 of the 20 threeletter items (with no false recall) and accurately recognized 18. The generating patterns, he claims, were the decimal expansion of 1/2012, excluding the initial zeroes, and the most famous lines of Martin Luther King, Jr.'s, “I Have a Dream” speech, skipping every other letter and excluding one repeated item. In both cases I hand-confirmed that the "re-presented" lists conformed to the purported generation procedure. Hand application of the two-tailed Fisher's exact test shows recall to match significantly less well to the "re-presented" lists than do the hand-confirmation results (both $\mathrm{p}$ 's $<.001$ ). At a $\mathrm{p}<.05$ confidence level, the recognition results are statistically significant for the three-digit items but not the three-letter items. 
Figure 2: Number correct out of 20 as judged by comparison with the lists "re-presented" by seeming-Alan, for my recall guesses, my recognition-test guesses, and my hand confirmation of the purported generating procedure. Error bars for "recalled" and "recognized" are hand calculated 95\% confidence intervals using the normal approximation. Error bars for the handconfirmed data use the "rule of three". See the body of the text for statistical tests.

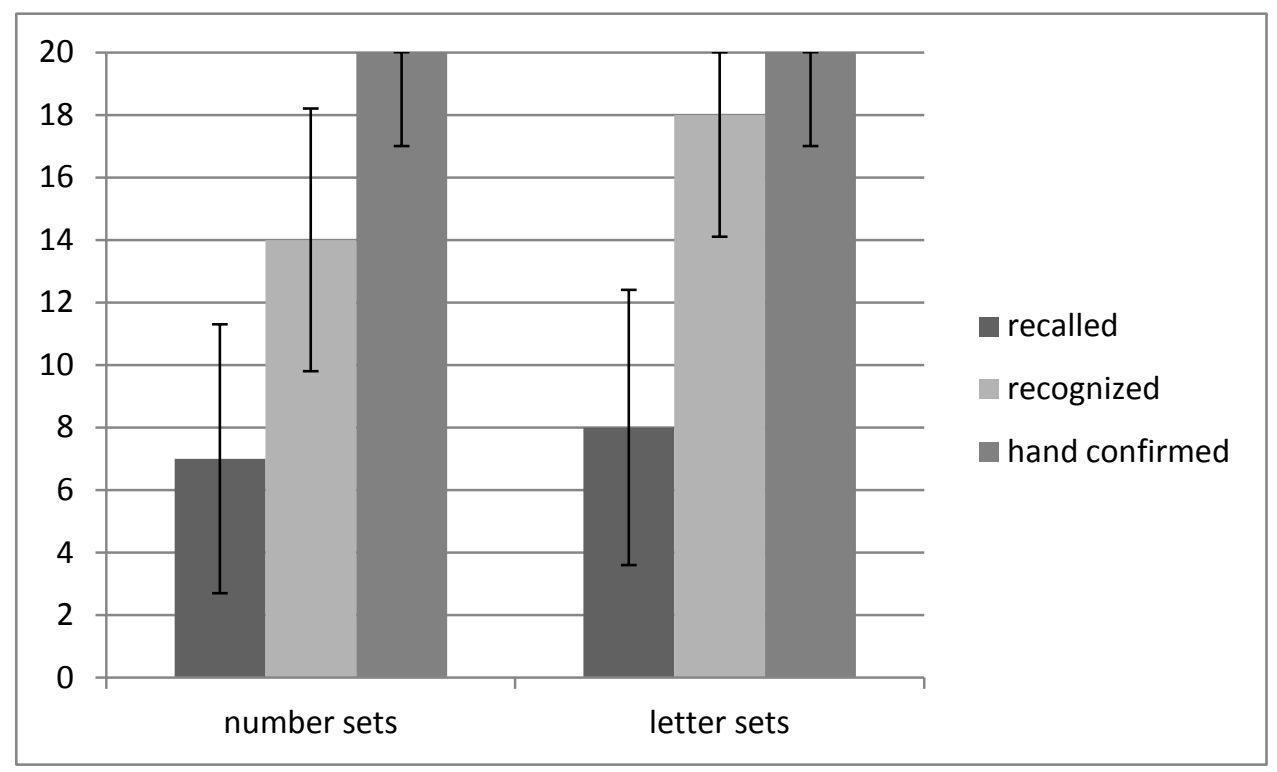


I found myself trying hard in both memory tasks. Since I am inclined to believe that the external world does exist and thus that some other people might read what I now appear to be writing, I was motivated not to come across as stupid. This created a substantial incentive to answer correctly which I did not feel as strongly in Experiment 1.

Discussion. I believe the most natural interpretation of these results is that something existed in the external world that retained the originally presented information across my gap of memory.

Alternative interpretations are possible as always. The question is whether those alternative interpretations are scientifically attractive. One alternative interpretation is that the laws connecting experiences are temporally gappy or even temporally backwards. There might have been a direct, unmediated connection between the experience of hearing the original auditory experience of "IAE", "DEM", etc., and later visually experiencing those same letter arrangements. If I am willing to countenance backward causation, then a neat explanation offers itself: I might have solipsistically concocted the generating patterns at the moment seeming-Alan seemed to be informing me of them, and then these generating patterns might have backwardly caused my initial auditory experiences and guesses. However, temporally backward causation seems a desperate move if I'm aiming to apply normal scientific standards as I conceptualize them. A somewhat less radical possibility is temporally gappy cross-modal causation from auditory experience at the beginning of the experiment to visual "re-presentation" later; but this requires, in addition to the somewhat uncomfortable provision of temporally gappy causation, a further seeming implausibility absent from the backward causation case - the seeming implausibility, similar to that in Experiment 1, of an unmediated law of experience that operates upon semantic contents of those experiences that are unrecognized as such by me at the time of 
the law's operation. In this case the relevant semantic contents would be nothing as elegant as primeness but rather the decimal expansion of one divided by the current calendar year, excluding the initial zeroes, and the English orthography of the words of a famous speech, skipping alternate letters and excluding one repeated triplet.

The thought occurs to me that some of the laws of external-world psychology, as I conceive of it, are also weird and semantical. For example, an advertisement might trigger a tangentially associated memory. But the crucial difference is this: In the case of external-world psychology, the semantic associations, even if not conscious, I assume to be grounded in mundane facts about neural firing patterns and the like. A bare solipsistic tendency to create and then recreate, unbeknownst to myself, the same partial orthography of a famous speech, while meanwhile being unable to produce that partial orthography when I consciously try to do so well, that's not impossible perhaps, but neither does it seem as natural a development of solipsism as does the view that the stability of experience should not exceed the stability of memory.

My argument would be defeated if I could have easily found some simple scheme, posthoc, that could generate twenty items including exactly those seven recalled numbers and eight recalled letter sets. My anti-solipsistic interpretation requires that there be only one plausible generating scheme for each set; otherwise there is no reason to think the unrecalled items would be the same on the initially presented list as on the subsequently presented list. So, then, what are the odds of a post-hoc fit of seven or more items from each set? Fortunately, very low about one in a million, given some plausible assumptions and the mathematics of combination. ${ }^{13}$

${ }^{13}$ Consider the odds of hitting one specific familiar sentence or one specific numbergenerating sequence. Given 1000 possible three-digit numbers, equally likely, or 1000 equally likely letter sets, the odds of exactly seven matches among the 20 items generated by that 
Perhaps, then, the best defense for solipsism, if it's not to collapse into a general radical skepticism about memory or induction or arithmetic, is temporally gappy forward causation grounded in unrecognized weird semantic features of the relevant experiences. I'm inclined to think this is a somewhat awkward position for the solipsistic hypothesis. But maybe I'm being too unsympathetic to solipsism? Maybe I should have expected that scientific laws would look somewhat weird in a solipsistic world, and rather unlike the scientific laws I think of as characteristic of the natural sciences and naturalistic psychology? So I have planned for myself one final experiment of a rather different sort.

\section{Experiment 3: Defeat at Chess.}

Method. Seeming-Alan has, if I recall, told me that he is good at chess. I believe that I stink at chess. Thus, I have arranged to play 20 games of speed chess against seeming-Alan, with a limit of approximately five seconds per move. If solipsism is true, nothing in the universe should exist that has chess-playing practical reasoning capacities that exceed my own, and so seeming-Alan should be unable to defeat me at rates above statistical chance. Figure 3 displays the procedure, as presented to me by a seeming camera held by a seeming Gerardo Sanchez.

specific sentence or number-generating scheme are approximately $\left(1 / 10^{3}\right)^{7}$ times 20 -choose- 7 possible arrangements (about $10^{6}$ ), i.e., approximately one in $10^{15}$. The odds of 8 or more matches add only negligibly to this probability. Even if we assume a billion possible simple generating schemes along roughly the lines I recall having suggested to seeming-Alan, the odds of a chance match of at least seven items out of 20 to any one of those billion generating schemes remain about one in a million (i.e., $10^{9} / 10^{15}=1 / 10^{6}$ ). If I'm aiming to exclude chances of $\mathrm{p} \geq .05$, that gives me a few orders of magnitude for relaxing the assumptions of this estimate. 
Figure 3: The procedure of Experiment 3.

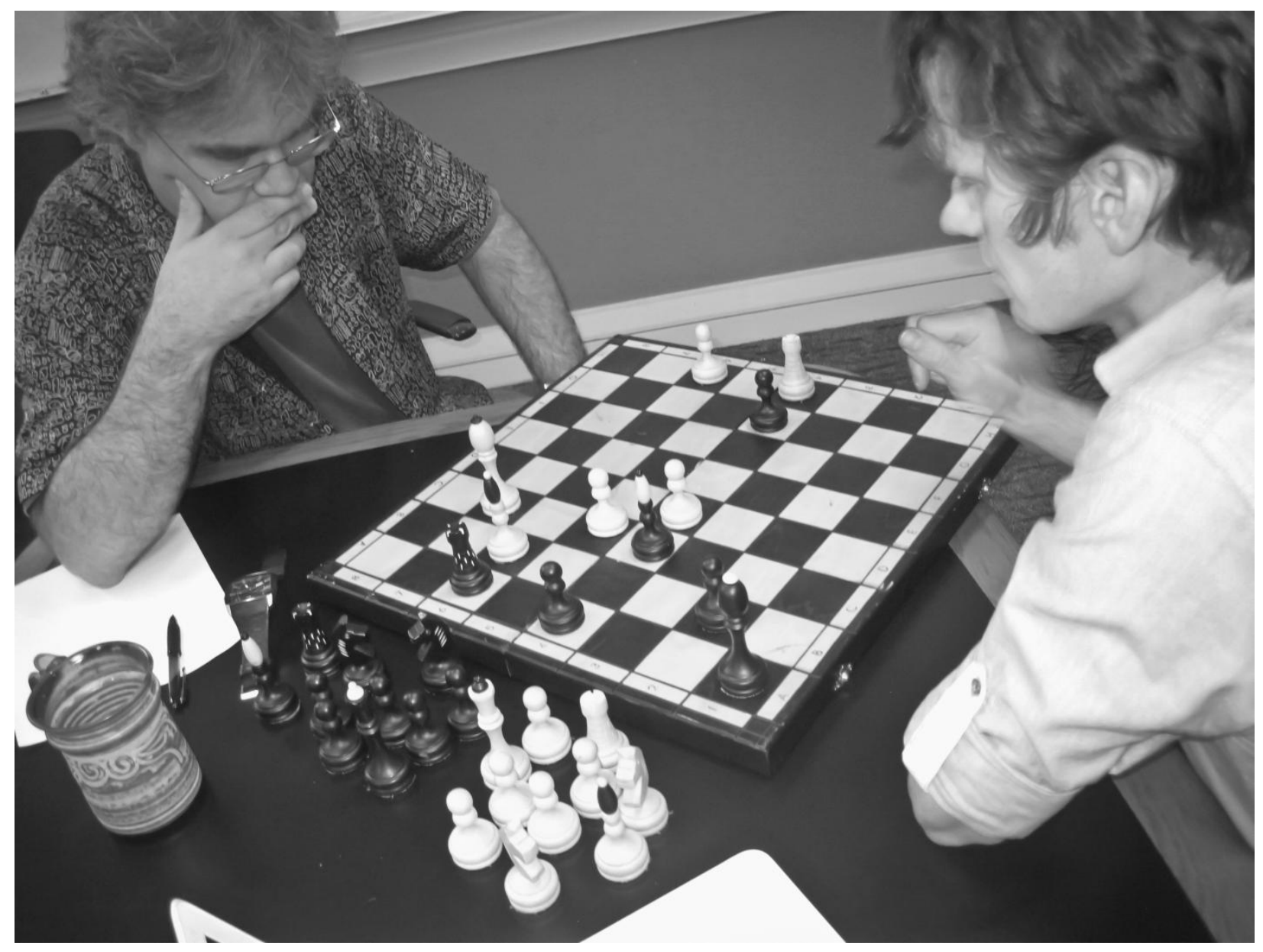


Results. Seeming-Alan defeated me in 17 games of 20, with one stalemate. $17 / 19$ is statistically higher than $50 \%$ with a p-value $<.001$ (hand calculated).

Discussion. It occurs to me that I might have hoped to lose, so as to generate results confirming my preferred hypothesis that the external world exists. Against this concern, I reassure myself with the following thoughts. If it was an unconscious desire to lose, then that implies that something exists in the world besides my stream of conscious experience, namely, an unconscious part of my mind, and thus radical solipsism as I have defined it is false. If it was, instead, a conscious desire to lose, I should have been able to detect it, barring an unusual degree of introspective skepticism. What I detected instead was a desire to win as many games as I could manage, given my background assumption that if Alan actually exists I would be hard pressed to win even one or two games. I found myself forcefully and repeatedly struck by the impression that the universe contained a practical intelligence superior to my own and bent on defeating me. The most natural scientific explanation of the pattern in my experience is that that impression was correct.

Does it matter that, if the external world exists in something like the form I think it does, some chess-playing programs could have defeated me as handily as seeming-Alan did? I don't see why it should. Whether the strategy and intentionality is manifested directly by a human being or instead through the medium of a human-programmed chess-playing computer - or in any other way - as long as that strategy and intentionality exceeds the abilities of my own conscious mind, the solipsistic hypothesis faces a substantial explanatory challenge. It can try to address this challenge by appealing to intrinsic relationships among experiences of mind relationships among seeming chess moves countered by other seeming chess moves whose 
power I only recognize in retrospect - but the more elegant unifying explanation of the results would seem to be the existence of a hostile goal-directed intelligence.

I could abandon the pursuit of explanation: It's a regularity unexplained, end of story. But why settle myself so quickly into defeat, when so natural an explanation suggests itself to me as worth exploration? Simply shrugging, when I am not forced to do so, runs contrary to the exploratory, scientific spirit of this exercise.

I might easily enough dream of being consistently defeated in chess. Maybe some dreamlike concoction of a seeming chess master could equally well explain my pattern of experience? But dreams of this sort, as I seem to remember, differ from the present experiment in one crucial way: They are vague on the specific moves or unrealistic about those moves. In the same way, I might dream of proving Fermat's last theorem. Such cases involve dream-like gappiness or irrationality or delusive credulity - the type of gappiness or irrationality or delusive credulity that might make me see nothing remarkable in discovering I am my own father or in discovering a new whole number between 5 and 6 . Genuine dream doubt might involve doubt about my basic rational capacities, but if so, such doubts outrun simply solipsistic doubts. And even if I am dreaming or in some other way concocting for myself an imaginary chess master, radical solipsism in the intended sense might still be defeated, if it implies that there is some unconscious part of my mind that excels at chess and on which I draw, unwittingly, to select those startlingly clever moves. If I consistently experience clever and perceptive chess moves that repeatedly exploit flaws in my own conscious strategizing, flaws that I experience as surprising, it seems hard to avoid the conclusion that something exists that exceeds my own conscious intelligence in at least this one area. 


\section{General Discussion.}

When I examine my stream of experience casually, nothing in it seems to compel the rejection of solipsism. My experience contains seeming representations of outward objects; it follows patterns unknown to me and that resist my will. But those basic facts of experience are readily compatible with the truth of radical solipsism. Once I find myself with solipsistic doubts, "here is a hand" does not help me recover; but neither do ambitious proofs in the spirit of Descartes and Kant seem to succeed. I could try to reconcile myself to the impossibility of proof, but that feels like giving up.

Fortunately, the external world hypothesis and the solipsistic hypothesis do appear to make different empirical predictions under certain conditions, at least when interpreted straightforwardly. The external world hypothesis predicts that I will see evidence of theoretical reasoning capacities, memorial retention, and practical reasoning capacities exceeding my own, while solipsism predicts the contrary. I can then scientifically test these predictions, avoiding begging the question by using only tools that are available to me from within a solipsistic perspective.

The results come out badly for solipsism. To escape my seemingly anti-solipsistic results requires either adopting other forms of radical skepticism in addition to solipsism (for example about memory, even in the short duration of these studies) or adopting increasingly ad hoc, strained, and convoluted accounts of the nature of the laws connecting one experience to the next.

Did I really need to do science to arrive at this conclusion, though? Maybe instead of running formal experiments could I have simply consulted long-term memory for evidence of 
my frustration by superior intelligences and the like? Surely so! And thus maybe also even before conducting these exercises I implicitly relied upon such evidence informally to support my knowledge that the external world exists. Indeed, it would be nice to grant this point, since then I can rightly say that I have known for a long time that the external world exists. But still, the present procedure, if successful, has several advantages over attempts to remember past frustrations and failures. For one thing, it achieves its goal despite conceding more to the skeptic from the outset, for example about long-term memory. For another, it more rigorously excludes chance and confirmation bias in evidence selection. And for still another, it forces me starkly and explicitly to consider the evidence and possible alternative explanations of it in light of specific and concrete pieces of data.

Perhaps it's worth noting that the best experiments I could concoct all involved pitting my intelligence against another intelligence, or against a device created by another intelligence a device or intelligence capable of generating semantic or strategic patterns that I could only subsequently appreciate. Whether this is an accidental feature of the experiments I happened to devise or whether it reflects some deeper truth, I am unsure. ${ }^{14}$

I conclude that the external world does in fact exist. To be clear, I don't at this point conclude anything about its metaphysical character. It is consistent with my experimental results that the external world be material or divine or an unconscious part of myself or an ectoplasmic computer, as long as it can host intelligence. I'll go out on a limb, though, and tentatively

\footnotetext{
${ }^{14}$ Maybe Fichte (1797/2000) and Hegel (1807/1977) wouldn't be surprised by this feature of my findings. See discussion in Beiser 2005 and Stern 2012. However, I share Stern's concerns about the force of such responses to solipsism as historically developed.
} 
conclude that Alan exists ${ }^{15}$ so that I may call him co-author, and I will do something that seems to me to be the act of circulating this essay for him and others to read. ${ }^{16}$

${ }^{15}$ Seeming-Alan adds: "Eric is correct that I exist. However, it's not clear I should accept that he exists. In the context of this micro-cosmos, I appear to be some sort of chessplaying god, and a god can't reason its way out of solipsism by the paths explored here."

${ }^{16}$ For helpful comments and discussion, thanks to James Beebe, Jenann Ismael, Pierre Keller, Noa Latham, Houston Smit, Jonathan Vogel, Chris Yeomans, students in my Winter 2011 senior seminar, and commenters on relevant posts at The Splintered Mind and the Experimental Philosophy blog. 


\section{$\underline{\text { References }}$}

Beebe, James (2009). The abductivist reply to skepticism. Philosophy \& Phenomenological Research, 79, 605-636.

Beiser, Frederick (2005). Hegel. New York: Routledge.

Berkeley, George (1710/1965). A treatise concerning the principles of human knowledge. In C.M. Turbayne, ed., Principles, dialogues, and philosophical correspondence. New York: Macmillan.

BonJour, Laurence (1985). The structure of empirical knowledge. Cambridge, MA: Harvard. BonJour, Laurence (2003). A version of internalist foundationalism. In L. BonJour and E. Sosa, Epistemic justification. Malden, MA: Blackwell.

Broughton, Janet (2002). Descartes's method of doubt. Princeton: Princeton.

DeRose, Keith (1995). Solving the skeptical problem. Philosophical Review, 104, 1-52.

Descartes, René (1641/1984). Meditations on first philosophy. In J. Cottingham, R. Stoothoff, and D. Murdoch, eds., The philosophical writings of Descartes, vol. II. Cambridge: Cambridge.

Dicker, Georges (2008). Kant's refutation of idealism. Noûs, 42, 80-108.

Dretske, Fred (2003). Skepticism: What perception teaches. In S. Luper, ed., The skeptics. Aldershot, England: Ashgate.

Duhem, Pierre (1906/1954). The aim and structure of physical theory. Trans. P.P. Wiener. Princeton: Princeton.

Fichte, Johann G. (1797/2000). Foundations of natural right. Ed. F. Neuhouser. Trans. M. Bauer. Cambridge: Cambridge.

Guyer, Paul (1987). Kant and the claims of knowledge. Cambridge: Cambridge. 
Hegel, G.W.F. (1807/1977). Phenomenology of spirit. Trans. A.V. Miller. Oxford: Oxford. Hume, David (1740/1978). A treatise of human nature, ed. L.A. Selby-Bigge and P.H. Nidditch. Oxford: Oxford.

Kant, Immanuel (1781/1787/1929). Critique of pure reason. Trans. N.K. Smith. New York: St Martin's.

Kuhn, Thomas S. (1962/1996). The Structure of Scientific Revolutions, $3^{\text {rd }}$ Edition. Chicago: Chicago.

Lakatos, Imre (1978). Philosophical papers, ed. J. Worrall and G. Currie. Cambridge: Cambridge.

Lewis, David (1996). Elusive knowledge. Australasian Journal of Philosophy, 74, 549-567.

Locke, John (1689/1975). Essay concerning human understanding, ed. P.H. Nidditch. Oxford: Oxford.

Mill, John Stuart (1867). An examination of Sir William Hamilton's philosophy. London: Longmans, Green, Reader, and Dyer.

Moore, G.E. (1939). Proof of an external world. Proceedings of the British Academy, 25, 273300.

Nolan, Lawrence, and Alan Nelson (2006). Proofs for the Existence of God. In Stephen Gaukroger, ed., The Blackwell Guide to Descartes' Meditations. Oxford: Blackwell. Peacocke, Christopher (2004). The realm of reason. Oxford: Oxford.

Popper, Karl R. (1934/1959). The logic of scientific discovery. New York: Basic.

Reichenbach, Hans (1938/2006). Experience and prediction. Notre Dame, IN: University of Notre Dame.

Russell, Bertrand (1912). The problems of philosophy. Oxford: Oxford. 
Russell, Bertrand (1914). Our knowledge of the external world. London: George Allen \& Unwin.

Schwitzgebel, Eric (2011). Perplexities of consciousness. Cambridge, MA: MIT.

Schwitzgebel, Eric (2012). Introspection, what? In D. Smithies and D. Stoljar, eds., Introspection and consciousness. Oxford: Oxford.

Schwitzgebel, Eric (2013). Hans Reichebach's cubical world and Elliott Sober's beach. Blog post at The Splintered Mind, March 19, http://schwitzsplinters.blogspot.com/2013/03/hans-reichenbachs-cubical-world-and.html

Searle, John R. (1980). Minds, brains, and programs. Behavioral and Brain Sciences, 3, 417457.

Searle, John R. (1984). Minds, brains and science. Cambridge, MA: Harvard.

Sober, Elliott (2011). Reichenbach's cubical universe and the problem of the external world. Synthese, 181, 3-21.

Stern, Robert (2012). Is Hegel's master-slave dialectic a refutation of solipsism? British Journal for the History of Philosophy, 20, 333-361.

Stroud, Barry (1984). The significance of philosophical scepticism. Oxford: Oxford. Stroud, Barry (1994). Kantian arguments, conceptual capacities and invulnerability. In P. Parrini, ed., Kant and contemporary epistemology. Dordrecht: Kluwer.

Vogel, Jonathan (1990). Cartesian skepticism and inference to the best explanation. Journal of Philosophy, 87, 658-666.

Vogel, Jonathan (2005). The refutation of skepticism. In M. Steup and E. Sosa, eds., Contemporary debates in epistemology. Malden, MA: Blackwell. 
Vogel, Jonathan (2008). Internalist responses to skepticism. In J. Greco, ed., The Oxford handbook of skepticism. Oxford: Oxford.

Williams, Michael (1991). Unnatural doubts. Cambridge, MA: Blackwell.

Wittgenstein, Ludwig (1950-1951/1974). On certainty. Ed. G.E.M. Anscombe and G.H. von Wright. Malden, MA: Blackwell. 